\title{
Implementation of an online emergency education programme at a public university in Mexico
}

\author{
P. González-Barranco*, I. Balderas-Rentería, P.C. Esquivel-Ferriño, Y.A. Gracia-Vásquez, E.E. Vásquez-Farías \\ Facultad de Ciencias Químicas/Faculty of Chemical Sciences, Universidad Autónoma de Nuevo León, México
}

\author{
Keywords \\ Teaching Method \\ Online Education \\ Technological Platform \\ COVID-19 \\ Mexico \\ ${ }^{*}$ Corresponding author \\ patricia.gonzalezbrn@uanl.edu.mx
}

\begin{abstract}
Summary: The Universidad Autónoma de Nuevo León (UANL) is a large public university situated in Monterrey, Mexico. Most of the programmes, including a pharmacy related programme (Químico Farmacéutico Biólogo/Chemist Pharmacist Biologist), were running at the university until the pandemic. A lockdown was put in place where it was established that schools and non-essential jobs should be carried out from home. Since then, the UANL has started a training effort to migrate all current classes to online emergency educational schemes. Microsoft Teams was designated as the main platform. Students and faculty members were trained in its use and, after one month, classes were successfully restarted on this platform. The chosen platform was used to create virtual classrooms, problem-based learning was encouraged, and videos and discussion panels were used especially in place of pre-COVID-19 planned laboratory classes. The semester ended with good results, but faculty member training continues and the adaptation to a better organised online programme is now running. Options to try to compensate the lack of in person laboratory classes are still being explored.
\end{abstract}

\section{Background and Context}

The Universidad Autónoma de Nuevo León (UANL) is a public university situated in Monterrey, Mexico. It has more than 206,000 students in high school and higher education and 1,157 students registered in the Químico Farmacéutico Biólogo/Chemist Pharmacist Biologist programme. Most of the educational programmes are in person, only a few continual education courses were given remotely, for which UANL used a platform called Nexus, for all media and educational resources. This platform is also used for University students to submit and evaluate homework for the in-person classes. Only approximately $10 \%$ of the University's staff had previously delivered lectures online, despite all of them having, as students, attended online continuous education programmes. On 17th March 2020, UANL decided to stop all in-person activities for students as recommended by the government and one week later this was extended to include faculty and administrative staff. The regular termly calendar was scheduled from 20th January to 19th June 2020, a 20-week term. The term was in its ninth week when the pandemic interrupted the learning schedule.

\section{Educational Description}

UANL reorganised in one week. The decision to use Microsoft Teams as the main platform for professor-student interactions was made for the entire University. The online courses continued to use Nexus as their main platform, together with Territorium Life. The Innovation and Digital Development Department was created, and training began for faculty members and students via tutorials and practical virtual sessions between peers. A complete 60-hour workshop was offered from January through March, with some faculty members enrolling so they also supported their co-workers in the use of the new platform. At the same time, a consultation survey was designed for faculty members and students about electronic devices and internet availability. Two options were given to the students with tech problems:

1. To be given more time to solve them and to take the remaining classes during summer; or

2. To withdraw from the classes from this term and to retake them next term, without any charge. 
Online classes started a month later and the original programme was delayed by two weeks in order to compensate for part of the training time (a total of 17 weeks). A webpage bringing together all contact information to support departments was developed, and a psychological support department was also considered; most of these structures were implemented using Microsoft Teams. Quality indicators were adapted to online modality such as, amongst others, response times in all of the departments (UANL, 2020a).

A description of some of the strategies implemented in the school are provided; problem-based learning was encouraged in most of the classes, especially for missed practical sessions; a few virtual labs or videos were valuable complementary tools for missed lab classes; using Microsoft Teams as the main platform, the recording of the sessions for classes and debates was mandatory in order to provide flexibility for students with technical issues at the time of the classes; class discussions or doubts were written directly into the Microsoft Teams general publications board for the same reason; collaborative work was encouraged to build knowledge using the archives board and the resolution of problems as a team; and complimentary videos or other resources were shared via Microsoft Teams to concentrate most of the materials in one place (UANL, 2020b).

As part of the Químico Farmacéutico Biólogo/Chemist Pharmacist Biologist programme quality control system, and in order to evaluate the success of the emergency online courses implemented during 2020 spring term, the following key performance indicators were established: average scores \pm standard deviation and student failure percentage. For this research the authors then compared the results with the 2019 autumn term.

\section{Outcomes and Recommendations}

Surveys showed that no faculty members or students suffered any technical issue. Ninety-five point seven percent (95.7\%) of the pharmacy students continued with their semester in an online modality, and only $4.3 \%$ chose to register next term taking the classes free of charge.

From the comparison the authors found that the results were: $85.67 \pm 3.89$ with 3.93 failure percentage during autumn 2019 semester versus $89.23 \pm 5.8$ with 0 failure percentage from past semester. The difference was statistically significant $(p=0.05)$ and the cause of this variation is being discussed (Means et al., 2010).

During the summer 2020, a Development of Teaching Abilities Related to Digital Strategy Course has been offered to all faculty members in order to establish better organisation and adaptation of all educational programmes to an online modality, in order to ensure an enriched and quality digital experience for the students.
The faculty will still continue to seek alternatives for the practical classes such as those taken in Basic Chemistry and Pharmaceutical Compounding. The upcoming term will still have mobility restrictions in place and the use of virtual labs (like MyDispense, for pharmaceutical practicals) and the introduction of a mixed model in person laboratory classes will be encouraged, as the state situation permits.

\section{References}

Means, B., Toyama, Y., Murphy, R., Bakia, M., \& Jones, K. (2010) Evaluation of Evidence-Based Practices in Online Learning. A MetaAnalysis and Review of Online Learning Studies. U.S. Department of Education. Available at: https://www2.ed.gov/rschstat/eval/tech/ evidence-based-practices/finalreport.pdf

UANL [Universidad Autónoma de Nuevo León]. (2020a). Estrategia digital UANL. Available at: https://estrategia-digital.uanl.mx/

UANL [Universidad Autónoma de Nuevo León]. (2020b). Tutorials MS TEAMS. Available at: https://estrategia-digital.uanl.mx/ calendario-de-capacitaciones-ms-teams/ 